\title{
Development of Brazilian prototypes for child psychodynamic psychotherapy and cognitive-behavioral therapy
}

\author{
Desenvolvimento de protótipos brasileiros de psicoterapia psicodinâmica \\ e terapia cognitivo-comportamental de crianças
}

\author{
Guilherme Pacheco Fiorini, ${ }^{1,2,3}$ (D) Vera Regina Röhnelt Ramires ${ }^{1}$ (D)
}

\begin{abstract}
Introduction: This study developed Brazilian psychodynamic psychotherapy (PDT) and cognitive-behavioral therapy (CBT) prototypes for children with internalizing disorders (ID) and externalizing disorders (ED).

Method: Eighteen Brazilian experts in PDT $(n=9)$ and CBT $(n=$ 9) rated the 100 items of the Child Psychotherapy Q-Set (CPQ) describing a hypothetical typical session based on their respective theoretical backgrounds for children with ID. They then rated the same items describing a hypothetical typical session for children with ED. A Q-type factor analysis with varimax rotation was performed.

Results: Expert correlations were high within each theoretical approach and each diagnostic category. The factor analysis identified three independent factors. CBT ratings concentrated on one factor, while PDT ratings loaded onto one factor describing treatment of children with ID and another factor describing treatment of children with ED.

Conclusion: The sole CBT prototype reflected a general conceptualization of this approach and was undifferentiated regarding treatment of children with ID and ED. The PDT prototype for children with ID provided evidence of a process focused on interpretation, while the PDT prototype for children with ED characterized a supportive process with attention to the therapeutic relationship. This infers greater variation in the PDT setting for children with different conditions.
\end{abstract}

Keywords: Psychotherapy, child psychology, psychodynamic psychotherapy, cognitive therapy.

\begin{abstract}
Resumo
Introdução: Este estudo desenvolveu protótipos brasileiros de psicoterapia psicodinâmica (PP) e terapia cognitivocomportamental (TCC) para crianças com transtornos internalizantes (TI) e externalizantes (TE).
\end{abstract}

Método: Dezoito experts brasileiros em PP $(n=9)$ e TCC $(n=9)$ classificaram os 100 itens do Child Psychotherapy Q-Set (CPQ) descrevendo uma sessão hipotética típica de acordo com suas respectivas abordagens teóricas para crianças com TI. Depois, eles classificaram os mesmos itens descrevendo uma sessão hipotética típica para crianças com TE. Foi realizada uma análise fatorial do tipo Q com rotação varimax.

Resultados: As correlações dos experts foram altas, considerando ambas as abordagens teóricas e as duas categorias diagnósticas. A análise fatorial gerou três fatores independentes. As avaliações da TCC concentraram-se em um fator, enquanto as avaliações da PP geraram um fator que descreveu o tratamento de crianças com TI e um outro fator que descreveu o tratamento de crianças com TE.

Conclusão: O protótipoúnico da TCC refletiu uma conceptualização geral dessa abordagem, indiscriminada em relação aos sintomas da criança. O protótipo da PP para crianças com TI evidenciou um processo focado na interpretação, enquanto o protótipo da PP para crianças com TE caracterizou um processo suportivo com atenção à relação terapêutica. Infere-se uma maior variação no processo em PP para crianças com diferentes sintomatologias. Descritores: Processos psicoterapêuticos, psicologia da criança, psicoterapia psicodinâmica, terapia cognitiva.

\footnotetext{
${ }^{1}$ Programa de Pós-Graduação em Psicologia, Universidade do Vale do Rio dos Sinos (UNISINOS), São Leopoldo, RS, Brazil. ${ }^{2}$ University College London, London, United Kingdom. ${ }^{3}$ Anna Freud National Centre for Children and Families, London, United Kingdom.

This article is based on the first author's master's thesis entitled "Brazilian prototypes for psychodynamic and cognitive-behavioral psychotherapies with children," presented in March 2018 at Universidade do Vale do Rio dos Sinos (UNISINOS), São Leopoldo, RS, Brazil. Part of this study was presented on a panel entitled "Child psychotherapy: looking into expectations, change process and psychotherapy prototypes" at the 49th International Annual Meeting of the Society for Psychotherapy Research, held in June 2018 in Amsterdam, the Netherlands.

Submitted Jun 11 2018, accepted for publication Oct 302018.

Suggested citation: Fiorini GP, Ramires VRR. Development of Brazilian prototypes for child psychodynamic psychotherapy and cognitive-behavioral therapy. Trends Psychiatry Psychother. 2019;41(2):149-158. http://dx.doi.org/10.1590/2237-6089-2018-0053
} 


\section{Introduction}

This study was designed to develop Brazilian psychodynamic psychotherapy (PDT) and cognitivebehavioral therapy (CBT) prototypes for children with internalizing disorders (ID) and externalizing disorders (ED). Over the last few years, an increasing body of evidence has been accumulating for the effectiveness of PDT and CBT for children with different symptoms, ${ }^{1,2}$ reinforcing the relevance of these treatments. However, studies that focus on how psychotherapies promote change are scarce. ${ }^{3}$

In an attempt to bridge this gap, researchers have examined the psychotherapeutic process, which consists of assessment of phenomena present throughout these treatments that could be associated with the outcomes, such as the therapists' interventions and the therapeutic relationships. The findings of these studies are relevant to promotion of more effective and parsimonious practices for therapists working in different contexts and from different backgrounds. ${ }^{3}$

In this context, Ablon and Jones ${ }^{4}$ made a significant contribution to the field of psychotherapy process research, developing the prototypes methodology. Psychotherapy prototypes are descriptions created by expert clinicians of an ideal or typical session for a specific therapeutic approach. These descriptions are used to profile the main characteristics of different intervention models (e.g., psychodynamic, cognitivebehavioral) and to assess whether real treatments correspond to their theoretical assumptions. ${ }^{4,5}$

Beyond providing a description of the features of treatments, psychotherapy prototypes are also useful for identifying which elements of treatment are common to all modalities (i.e., are common factors) and which are exclusive to a given approach (i.e., are specific factors). ${ }^{4,5}$ Furthermore, prototypes allow for analysis of which "active ingredients" correlate with outcomes, as already addressed in the field of adult psychotherapy research. ${ }^{4,6}$

Based on comparison of prototypes with real videorecorded psychotherapy sessions, studies have reported that PDT and CBT treatments exhibit characteristics of both theoretical approaches simultaneously. 4,5,7 Moreover, these studies have demonstrated that characteristics of the dyad influence how similar real sessions are to the prototypes.

\section{Child psychotherapy prototypes}

Goodman et al. ${ }^{8}$ were the first to develop child psychotherapy prototypes, using the Child Psychotherapy Q-Set (CPQ) ${ }^{9}$ which is an adaptation of the Psychotherapy Process Q-Set (PQS) ${ }^{10}$ for the child population. The $\mathrm{CPQ}$ is a child psychotherapy process assessment measure comprising 100 items that describe what can occur in a therapy session, including aspects of the child, the therapist, and the relationship between them.

Besides investigating the PDT and CBT prototypes for children, the authors of the above-mentioned study $^{10}$ also addressed the mentalization-focused approach (abbreviated in the original study as RF, for "reflective functioning", which is the operationalization of the construct of mentalization). The RF approach focuses on development of the mentalizing capacity, a construct that describes the capacity to understand one's own and others' behaviors in terms of underlying mental states. ${ }^{11}$

For the purposes of their study, Goodman et al. ${ }^{8}$ invited PDT, CBT, and RF expert clinicians to rate the CPQ items, aiming to describe an ideal session within each of their respective approaches. After gathering all the expert clinicians' ratings, the authors conducted a factor analysis. The investigation found that the PDT and CBT ratings loaded onto two distinct factors, while the RF ratings were spread across those two conceptualizations, not constituting a third factor. These results supported the conclusion that, according to the CPQ items, PDT and CBT processes with children comprise two empirically distinguished treatment modalities, while development of the mentalizing capacity is a common factor present in both approaches.

After formulating the prototypes, the authors calculated correlations between them. Contrary to the data found in Ablon and Jones' original study, ${ }^{4}$ where PDT and CBT prototypes for adults presented an almost null correlation, ${ }^{12}$ all of the child psychotherapy prototypes were significantly correlated. According to the authors, these findings indicated that child psychotherapy processes share more elements than adult psychotherapies, with emphasis on the therapeutic relationship. ${ }^{8}$

The PDT and CBT prototypes developed by Goodman et al. ${ }^{8}$ were subsequently employed by other authors to analyze video-recorded psychotherapies. For instance, Gastaud et al. ${ }^{13}$ used them to investigate the first year of PDT with two children in Brazil. One of the patients in this study was a boy diagnosed with adjustment disorder and dysthymia. He began his treatment when he was seven years old. The other was a boy who was eight years old at onset, diagnosed with Asperger Syndrome.

The data analysis showed that the first treatment was positively correlated with both prototypes, while the second did not exhibit significant correlations with either prototype. The authors discussed how some 
characteristics of the patients and the therapists might have influenced these results. ${ }^{13}$

According to Gastaud et al., ${ }^{13}$ the presence of CBT features in the first treatment may indicate that children with a precarious psychic structure require greater support from the psychodynamic psychotherapist, allowing for development of a capacity to explore their feelings in depth in further stages of the treatment. Whereas the second treatment, with a similarity to none of the prototypes, may have occurred following the therapist's identification of the child's specific needs. In that case, the therapist could have chosen to strengthen the therapeutic alliance and not adopt typical psychodynamic or cognitive-behavioral techniques.

Agreeing with the findings of Gastaud et al., ${ }^{13}$ other studies have presented a similar trend regarding the levels of similarities between real sessions and child psychotherapy prototypes. For example, Ramires et al. ${ }^{14}$ employed the PDT, CBT, and RF prototypes to analyze four years of PDT with a boy diagnosed with disruptive mood dysregulation disorder who was seven years old at referral.

In this case, a high level of similarity to all prototypes was also detected. The authors stated that the patient's symptomatology required the therapist to employ several different psychotherapy techniques. The interpretative stance and pointing out defenses, typical of the PDT prototype, were present throughout the treatment; however, the patient was also mobilized. To help the patient manage his strong feelings and impulses, the therapist sought to promote his mentalization, a prototypical characteristic of RF, and to use more directive and supportive techniques, typical of the CBT approach. ${ }^{14}$

Similar to studies with adult patients, studies of child psychotherapy prototypes have indicated that psychotherapies do not always correspond to their theoretical assumptions and that one treatment may simultaneously exhibit characteristics of different approaches. ${ }^{8,13,15}$ Likewise, there is evidence that characteristics of the dyad may influence the degree of similarity between the treatment and the prototypes. ${ }^{13,15}$

However, despite development of the PDT, CBT, and RF prototypes by Goodman et al., ${ }^{8}$ there are still gaps regarding prototypical psychotherapy processes with children. A lack of prototypes focusing on specific regions may be an obstacle to analysis of the psychotherapeutic processes performed in different locations, considering that conceptions about such processes may vary between countries or continents. Furthermore, development of prototypes focusing on specific symptomatic conditions may contribute to our understanding of how different approaches meet their patients' needs and of which treatments are best suited to each case. As indicated in previous studies of prototypes, some children may benefit from more structured and directive settings, while others may present better outcomes in nondirective settings. ${ }^{13,15}$

In the present study, we considered children's symptoms according to a dimensional disorder classification. This form of categorization is useful because it provides a complete understanding of psychopathologies, considering comorbidities, chronicity, and the existence of illness in a developmental continuum. ${ }^{16}$ This type of classification is widely employed in child psychology, with ID and ED being the most evident dimensions. ${ }^{17}$

Children who suffer from ID tend to feel their problems "inside" themselves, ${ }^{18}$ and their conditions are characterized by inhibition and poor interaction with peers and the environment. ${ }^{19}$ These symptoms include withdrawal and anxiety syndromes and also depression.

In contrast, children with ED present behavioral patterns such as lack of control and acting out. ${ }^{20}$ Unlike children with ID, these individuals' emotions, cognitions, and conflicts are expressed in the environment. These conditions include conduct and oppositional-defiant disorders. ${ }^{19}$

Therefore, the objective of this study was to develop Brazilian PDT and CBT prototypes for children with ID and ED. The following hypotheses were tested: 1 ) expert clinicians should exhibit a high degree of agreement regarding the conceptualization of sessions for children with ID and ED within their respective theoretical approaches; 2) based on the consideration that the Q methodology could differentiate the PDT and CBT prototypical processes in various previous studies $4,8,21$ and that the children's psychopathological conditions impact the therapeutic process and the degree of similarity to the prototypes, ${ }^{13,14}$ it was expected that the expert clinicians' ratings would generate four distinct factors, differentiating both theoretical approaches for both types of diagnoses.

\section{Method}

\section{Participants}

Eighteen expert child psychotherapy clinicians from the psychodynamic $(n=9)$ and cognitive-behavioral ( $n$ =9) approaches participated in this study. Contact was made with the therapists selected by communication with recognized training institutions and through peer referral. The criteria for expertise were as follows: at 
least 5 years of clinical practice with children, peer recognition of expertise, and experience as a teacher and/or supervisor in Brazilian higher education institutions. The sample size is equivalent to previous studies that have employed the same methodology, 4,8 and was defined according to the data analysis methods, which required a greater number of observations (the $100 \mathrm{CPQ}$ items) than variables (the expert clinicians).

The expert PDT clinicians had a mean of 18.44 years of clinical experience with children ( $S D=12.25)$, while the expert CBT clinicians had a mean of 12.22 years $(S D=6.59)$. All participants had specializations in psychotherapy and 11 had undergone specific training for child therapy (61\%); 7 had a master's degree, and 5 had a doctorate in the field of child psychotherapy (39\% and $28 \%$, respectively). According to a t-test for independent samples, the mean length of experience was equivalent between groups $(t=1.34, p<0.20)$. The expert clinicians' ratings were used to investigate prototypical conceptions for children with ID and ED, employing the CPQ.

\section{Instrument}

The CPQ is an ipsative measure used to describe child psychotherapy sessions. Developed by Schneider and Jones $^{9,22}$ and formulated in a pan-theoretical manner, it can be employed in the assessment of sessions using different approaches, either in manualized or conventional treatments. The instrument comprises 100 items that describe characteristics of the therapist, the child, and the dyad's interaction.

In the traditional version of the $\mathrm{CPQ}$, pairs of independent judges rate video-recorded sessions, sorting a specified number of items along a continuum from the least to the most characteristic (scores ranging from 1 to 9). In this methodology, a forced choice is made, resulting in a normal distribution of the items. Conversely, to determine the prototypes, raters have the liberty to assign any score to each item.

The CPQ was translated and adapted to Brazilian Portuguese by Ramires and Schneider. ${ }^{23}$ The CPQ has achieved good reliability indices in previous studies. ${ }^{8,24-26}$

\section{Data collection and analysis}

Participants were contacted via email and given links to the research forms. All ethical considerations were respected and the study was approved by the Research Ethics Committee at the university where it was conducted. The expert clinicians signed an informed consent form and filled out a sociodemographic questionnaire, which was designed to characterize the sample. Participants were asked to rate the 100 items of the CPQ in order to describe a hypothetical typical psychotherapy session for children with ID that followed the guidelines of their respective theoretical approach. Next, they were asked to rate the same 100 items in order to describe a hypothetical typical psychotherapy session for children with ED. Prior to the rating process, definitions of both ID and ED were provided to participants. The expert clinicians were also requested to consider the intermediate phase of treatment, i.e., after the contract has been established, but before the discharge discussion begins.

In this study, an adapted form of scoring was used for the CPQ, by which each item was rated in a non-forced manner using a Likert scale ranging from -4 (highly negatively characteristic) to +4 (highly characteristic), as employed by Goodman et al. ${ }^{8}$ Items with ratings around 0 were considered neutral or irrelevant. The expert clinicians' ratings were converted to z-scores, which were then used in the subsequent statistical analyses.

Regarding the data analysis, in an initial step, Cronbach's alpha was calculated to evaluate the expert clinicians' agreement on the prototypical model for their approaches for children with ID and ED. In a second step, ratings were used to conduct Q-type factor analysis with varimax rotation to test whether the protocols generated empirically distinct factors (prototypes). In a third step, Spearman coefficients were calculated for correlations between the Brazilian PDT and CBT prototypes and with the international prototypes published by Goodman et al., ${ }^{8}$ to investigate the degree of similarity between these treatment models. All data were analyzed with SPSS version 24.0.

\section{Results}

The indices of agreement between the psychodynamic psychotherapists, calculated as Cronbach's alpha, were 0.93 for treatment of children with ID and 0.92 for treatment of children with ED. Similarly, levels of agreement between the cognitive-behavioral therapists were 0.92 and 0.91 , in the same order. These findings indicate that the participants shared highly similar conceptualizations of these prototypical treatment models.

The experts' ratings were subjected to Q-type factor analysis with varimax rotation. Unexpectedly, three factors were identified that explained $66.41 \%$ of the items' variation. All CBT prototypical ratings loaded significantly onto factor 1 (variation between 0.50 and 0.79 , mean $=0.71$ ), including ratings for children with ID and for children with ED. All PDT ratings for children with ID had significant loadings on the second factor, 
(variation between 0.41 and 0.89 , mean $=0.73$ ). All PDT protocols for children with ED loaded significantly onto the third factor (variation between 0.56 and 0.79 , mean $=0.69$ ).

In the last step, Spearman correlation coefficients were calculated to test for similarity between prototypes. None of the three factors exhibited significant correlations with any of the others, as shown in Table 1. Next, the three factors were tested for correlations with the prototypes published by Goodman et al. ${ }^{8}$ Factor 1 exhibited a high positive correlation ${ }^{27}$ with the international CBT prototype ( $\mathrm{s}=0.86, \mathrm{p}<0.01)$ and a significant but weak correlation ${ }^{27}$ with the international PDT ( $s=0.22, \mathrm{p}<0.05$ ) prototype. Factor 2 presented a high positive correlation ${ }^{27}$ with the international PDT prototype ( $s=0.71, p<0.01$ ), while factor 3 had a moderate positive correlation with the same prototype ( $\mathrm{s}=0.52, \mathrm{p}<0.01)$.

Tables 2, 3, and 4 present the 15 most and least characteristic items in each factor. It is noteworthy that each prototype is composed of the $100 \mathrm{CPQ}$ items in different orders and it should be pointed out that the decision to present 15 items is arbitrary. It should be highlighted that item 18, "therapist is judgmental and conveys lack of acceptance," is present among the items least characteristic of all prototypes, while item 48, "therapist sets limits," is among the items most characteristic of CBT and PDT for children with ED. Similarly, item 24, "therapist's emotional conflicts intrude into the relationship," is listed among the items least characteristic of CBT and PDT for children with ED, and item 98, "the therapeutic relationship is discussed," is among the items most characteristic of both PDT prototypes. Item 46, "therapist interprets the meaning of child's play," is listed among the items least characteristic of the CBT prototype, but among those most characteristic of PDT for children with ID. The inverse occurs with item 93, "therapist is neutral," which is among the items most characteristic of PDT for children with ID and those least characteristic of CBT.
Items 40, "child communicates without affect," 56, "child is distant from his or her feelings," and 95, "child's play lacks spontaneity," are found among those least characteristic of CBT and PDT for children with ED. In contrast, items 17 "therapist actively exerts control over the interaction," 27 , "there is a focus on helping the child plan behavior outside the session," 37, "therapist behaves in a didactic manner," and 87, "therapist informs child of the potential impact of his or her behavior on others," are among the items most characteristic of CBT and least characteristic of PDT for children with ID. Furthermore, item 55, "therapist directly rewards desirable behaviors," is characteristic of the CBT prototype, but is not characteristic of either PDT prototype.

\section{Discussion}

This study investigated Brazilian expert clinicians' prototypical conceptions regarding the PDT and CBT therapeutic processes for children with ID and ED. Factor analysis identified three distinct conceptualizations of child psychotherapies.

Similar to what has been observed in previous studies, Brazilian expert clinicians, within their respective approaches, exhibited a high level of agreement on the characteristics of prototypical sessions for children with different symptoms. The high degree of consistency between ratings confirmed hypothesis 1 raised in this study. Regarding factor analysis, CBT ratings were concentrated on only one factor. According to the data obtained, the CBT psychotherapeutic process for children is characterized by greater therapist control, in that they actively exert control over the interaction (CPQ item 17), behave in a didactic manner (item 37), attempt to modify distortions in the child's beliefs (item 57), and help the child to manage his or her feelings (item 82). Within this approach, there is also an emphasis on behaviors and their unfolding, either inside

Table 1 - Spearman correlation coefficients between prototypes

\begin{tabular}{lccccc}
\hline & CBT & PDT-INT & PDT-EXT & CBT-2016 & PDT-2016 \\
\hline CBT & - & & & & \\
PDT-INT & 0.10 & - & & & \\
PDT-EXT & 0.01 & 0.01 & - & - & - \\
CBT-2016 & $0.86^{*}$ & 0.17 & 0.11 & $0.36^{*}$ & - \\
PDT-2016 & $0.22^{+}$ & $0.71^{*}$ & $0.52^{*}$ & & \\
\hline
\end{tabular}

$\mathrm{CBT}=$ Brazilian cognitive-behavioral therapy prototype; CBT-2016 = international cognitive-behavioral therapy prototype; PDT-2016 = international psychodynamic psychotherapy prototype; PDT-EXT = Brazilian psychodynamic psychotherapy prototype for children with externalizing disorders; PDT-INT = Brazilian psychodynamic psychotherapy prototype for children with internalizing disorders.

$* p<.01 ;{ }^{\dagger} p<.05$. 
or outside the sessions (items 55, 27, and 87). This characterization corresponds to the literature on this approach, which focuses on the relationship between feelings, thoughts, and behaviors in a more structured setting. ${ }^{28,29}$

Considering the availability of different treatment manuals, it is inferred that the CBT therapeutic process is adapted to the patient's psychopathology. For example, in the treatment of children with ID, the therapeutic work may focus on taking the child from a passive stance and enabling them to face their negative and ruminative thoughts that should be changed. ${ }^{30}$ In this manner, there is intense monitoring of the child's thoughts and activities and the therapist helps the child to engage in pleasurable activities that they do not perform or have stopped performing. ${ }^{31}$ In turn, systematic desensitization is used for treatment of children with anxiety, wherein techniques of exposure to anxiogenic situations and relaxation are employed. ${ }^{32,33}$

Concerning CBT for children with ED, this approach primarily focuses on developing strategies to cope with anger, frustration, and disruptive behaviors. Techniques that are often employed include identification of previous factors and consequences of aggressive behaviors, development of recognition and regulation of anger expressions, and testing of socially appropriate behaviors that can replace disruptive reactions. ${ }^{34,35}$

Intriguingly, the findings of the present study indicate that there are no conceptually distinct models of the prototypical CBT processes for children with ID and ED. Despite the variety of manuals for treatment of different psychopathologies employing CBT, the

Table 2 - Most and least characteristic items for the Brazilian CBT prototype

\begin{tabular}{|c|c|c|}
\hline Item & Item description & z-score \\
\hline \multicolumn{3}{|c|}{15 most characteristic items } \\
\hline Item 55 & T directly rewards desirable behaviors. & 1.75154 \\
\hline Item 27 & There is a focus on helping $C$ plan behavior outside the session. & 1.70854 \\
\hline Item 57 & T attempts to modify distortions in C's beliefs. & 1.63523 \\
\hline Item 17 & T actively exerts control over the interaction. & 1.62019 \\
\hline Item 37 & $\mathrm{~T}$ behaves in a didactic manner. & 1.59235 \\
\hline Item 68 & Real rather than fantasized meanings of experience are actively differentiated. & 1.18621 \\
\hline Item 87 & $\mathrm{~T}$ informs $\mathrm{C}$ of the potential impact of his or her behavior on others. & 1.1524 \\
\hline Item 77 & T's interaction with $C$ is sensitive to the C's level of development. & 1.05425 \\
\hline Item 3 & T's remarks are aimed at encouraging C's speech. & 1.01292 \\
\hline Item 82 & $\mathrm{~T}$ helps $\mathrm{C}$ manage feelings. & 0.98647 \\
\hline Item 64 & C draws $\mathrm{T}$ into play. & 0.98073 \\
\hline Item 74 & Humor is used. & 0.96376 \\
\hline Item 4 & There is discussion of why $C$ is in therapy. & 0.95799 \\
\hline Item 48 & T sets limits. & 0.89379 \\
\hline Item 99 & T offers help or guidance. & 0.88613 \\
\hline \multicolumn{3}{|c|}{15 least characteristic items } \\
\hline Item 9 & $\mathrm{~T}$ is nonresponsive [vs. affectively engaged]. & -2.38352 \\
\hline Item 24 & T's emotional conflicts intrude into the relationship. & -2.13738 \\
\hline Item 41 & C does not feel understood by the therapist. & -2.1017 \\
\hline Item 42 & C ignores or rejects T's comments and observations. & -1.87968 \\
\hline Item 18 & $\mathrm{~T}$ is judgmental and conveys lack of acceptance. & -1.77472 \\
\hline Item 44 & C feels wary or suspicious [vs. trusting and secure]. & -1.69582 \\
\hline Item 56 & C is distant from his or her feelings. & -1.67876 \\
\hline Item 40 & C communicates without affect & -1.65156 \\
\hline Item 46 & T interprets the meaning of C's play. & -1.63852 \\
\hline Item 93 & $T$ is neutral. & -1.59413 \\
\hline Item 49 & C conveys or expresses mixed or conflicted feelings about the T. & -1.45069 \\
\hline Item 95 & C's play lacks spontaneity. & -1.41247 \\
\hline Item 1 & C expresses negative feelings toward $\mathrm{T}$ [vs. expresses approval or admiration]. & -1.30022 \\
\hline Item 11 & Sexual feelings or thoughts emerge. & -1.28182 \\
\hline Item 26 & C is socially misattuned or inappropriate. & -1.27813 \\
\hline
\end{tabular}

$\mathrm{C}=$ child $; \mathrm{T}=$ therapist. 
characteristics of the psychotherapeutic process within this approach may remain quite similar when treating different psychopathologies.

One hypothesis raised for this conceptual pattern addresses the model in which the treatment manuals are applied, developed, and validated. Often underpinned by experimental designs, such programs may not accurately reflect usual clinical practice. ${ }^{36}$ In contrast, in the present study examinations were performed on conceptions of typical psychotherapeutic processes and the results may demonstrate greater parsimony in CBT clinical practice in relation to the multiplicity of protocols.

The CBT factor may constitute a general conceptualization of this approach, applicable to children with different clinical problems. In general, according to
Stallard, ${ }^{31}$ CBT treatment protocols typically begin with a psychoeducational approach. In the subsequent steps, the therapist works on identification and management of the child's emotional states as well as recognition and substitution of maladaptive cognitions. Finally, there is a behavioral focus in which the child's experiences are used as a basis for acquiring new behaviors that promote a better capacity to deal with problems.

Another hypothesis raised is that the CPQ could not capture subtleties of CBT that would differentiate between treatments for children with ID and ED. For example, one of the most prevalent CBT approaches for children with ED is focused on parent training. ${ }^{37-39}$ In this regard, the CPQ may not be suitable for describing these treatments since its items are specifically focused on sessions with the child.

Table 3 - Most and least characteristic items for the Brazilian PDT prototype for children with internalizing disorders

\begin{tabular}{|c|c|c|}
\hline Item & Item description & z-score \\
\hline \multicolumn{3}{|c|}{15 most characteristic items } \\
\hline Item 93 & $\mathrm{~T}$ is neutral. & 1.68598 \\
\hline Item 67 & T interprets warded-off or unconscious wishes, feelings, or ideas. & 1.59958 \\
\hline Item 46 & T interprets the meaning of C's play. & 1.59498 \\
\hline Item 36 & T points out C's use of defenses & 1.27224 \\
\hline Item 90 & C's dreams or fantasies are discussed. & 1.26531 \\
\hline Item 71 & $C$ engages in make-believe play. & 1.24598 \\
\hline Item 92 & C's feelings or perceptions are linked to situations or behavior in the past. & 1.16181 \\
\hline Item 76 & T makes links between C's feelings and experience. & 1.1147 \\
\hline Item 28 & T accurately perceives the therapeutic process. & 1.08684 \\
\hline Item 29 & The quality of C's play is fluid, absorbed [vs. fragmented, sporadic]. & 1.07079 \\
\hline Item 94 & C feels sad or depressed [vs. cheerful and joyous]. & 1.06808 \\
\hline Item 97 & T emphasizes verbalization of internal states and affects. & 1.03954 \\
\hline Item 35 & C's self-image is a theme & 1.0348 \\
\hline Item 98 & The therapy relationship is discussed. & 1.03219 \\
\hline Item 62 & T points out a recurrent theme in the C's experience or conduct. & 1.02552 \\
\hline \multicolumn{3}{|c|}{15 least characteristic items } \\
\hline Item 37 & T behaves in a didactic manner. & -2.22772 \\
\hline Item 55 & T directly rewards desirable behaviors. & -2.12517 \\
\hline Item 17 & T actively exerts control over the interaction. & -2.11295 \\
\hline Item 89 & T acts to strengthen existing defenses. & -1.90235 \\
\hline Item 27 & There is a focus on helping the $\mathrm{C}$ plan behavior outside the session. & -1.67804 \\
\hline Item 20 & $\mathrm{C}$ is provocative; challenges the $\mathrm{T}$ or rules and boundaries of the therapy hour & -1.65222 \\
\hline Item 9 & $\mathrm{~T}$ is nonresponsive [vs. affectively engaged]. & -1.61633 \\
\hline Item 21 & T self-discloses. & -1.60836 \\
\hline Item 18 & $\mathrm{~T}$ is judgmental and conveys lack of acceptance. & -1.54588 \\
\hline Item 12 & T models unspoken or unelaborated emotions. & -1.52111 \\
\hline Item 87 & $\mathrm{~T}$ informs $\mathrm{C}$ of the potential impact of his or her behavior on others. & -1.3667 \\
\hline Item 39 & $C$ is competitive, rivalrous with the $T$. & -1.33474 \\
\hline Item 42 & C ignores or rejects T's comments and observations. & -1.31019 \\
\hline Item 83 & $\mathrm{C}$ is demanding. & -1.30329 \\
\hline Item 66 & $\mathrm{~T}$ is directly reassuring. & -1.30164 \\
\hline
\end{tabular}

$\mathrm{C}=$ child; $\mathrm{T}=$ therapist. 
In relation to the second factor, comprising PDT ratings for children with ID, a psychotherapeutic process was identified and characterized by a neutral therapist (item 93) who interprets the child's play and unconscious contents (items 46,67 ) and points out their defenses (item 36). The PDT prototype for children with ID resembled the classical PDT assumptions that include the understanding of a dynamic unconscious and the phenomena of transference, countertransference, and resistance. ${ }^{40,41}$

The third factor contained the experts' ratings regarding the PDT process for children with ED. In this prototype, an emphasis on the child items was identified (i.e., items 20, 25, 39, 72, and 83). These findings highlight how demanding and possibly mobilizing these children may be in the therapeutic setting. Regarding therapist items, this treatment modality prioritizes the therapeutic relationship (item 98) and its possible connections with other relationships (item 100). Furthermore, the therapist's tolerant stance when faced with the child's strong affects and impulses (item 45) indicates that attention must be paid to countertransferential reactions when treating children with these conditions. This was also identified in a previous study using the CPQ. ${ }^{14}$

While the Brazilian PDT prototype for children with ID and the Brazilian CBT prototype resembled the international prototypes, the conceptualization of PDT for children with ED presented in this study reveals a prototypical process distinct from previously published

Table 4 - Most and least characteristic items for the Brazilian PDT prototype for children with externalizing disorders

\begin{tabular}{|c|c|c|}
\hline Item & Item description & z-score \\
\hline \multicolumn{3}{|c|}{15 most characteristic items } \\
\hline Item 20 & $\mathrm{C}$ is provocative; challenges the $\mathrm{T}$ or rules and boundaries of the therapy hour. & 1.93796 \\
\hline Item 39 & C is competitive, rivalrous with the $T$. & 1.85937 \\
\hline Item 25 & $\mathrm{C}$ has difficulty leaving the session. & 1.58184 \\
\hline Item 83 & $\mathrm{C}$ is demanding. & 1.51339 \\
\hline Item 72 & $\mathrm{C}$ is active. & 1.42051 \\
\hline Item 84 & C expresses anger or aggressive feelings. & 1.40056 \\
\hline Item 58 & C appears unwilling to examine thoughts, reactions, or motivations related to problems. & 1.29129 \\
\hline Item 1 & C expresses negative feelings toward T [vs. expresses approval or admiration]. & 1.26032 \\
\hline Item 34 & C blames others, or external forces, for difficulties. & 1.24306 \\
\hline Item 42 & C ignores or rejects therapist's comments and observations. & 1.17397 \\
\hline Item 48 & T sets limits. & 1.07023 \\
\hline Item 98 & The therapy relationship is discussed. & 1.00936 \\
\hline Item 49 & C conveys or expresses mixed or conflicted feelings about the $\mathrm{T}$. & 0.97405 \\
\hline Item 100 & T draws connections between the therapeutic relationship and other relationships. & 0.92728 \\
\hline Item 45 & T tolerates C's strong affect or impulses. & 0.9164 \\
\hline \multicolumn{3}{|c|}{15 least characteristic items } \\
\hline Item 078 & C is compliant. & -2.19431 \\
\hline Item 053 & C conveys awareness of own internal difficulties. & -2.12946 \\
\hline Item 061 & C feels shy and embarrassed [vs. un-self-conscious and assured]. & -2.05707 \\
\hline Item 024 & T's emotional conflicts intrude into the relationship. & -1.88034 \\
\hline Item 080 & C behaves in a dependent fashion [vs. insists on independence]. & -1.66623 \\
\hline Item 029 & The quality of C's play is fluid, absorbed [vs. fragmented, sporadic]. & -1.65251 \\
\hline Item 070 & C struggles to control feelings or impulses. & -1.64499 \\
\hline Item 018 & $\mathrm{~T}$ is judgmental and conveys lack of acceptance. & -1.54903 \\
\hline Item 095 & C's play lacks spontaneity. & -1.54041 \\
\hline Item 055 & T directly rewards desirable behaviors. & -1.43581 \\
\hline Item 085 & C's aggression is directed toward self. & -1.3889 \\
\hline Item 040 & C communicates without affect & -1.38718 \\
\hline Item 073 & C expresses fears or displays phobic behavior. & -1.38657 \\
\hline Item 054 & $\mathrm{C}$ is clear and organized in verbal expression. & -1.24431 \\
\hline Item 056 & $\mathrm{C}$ is distant from his or her feelings. & -1.15499 \\
\hline
\end{tabular}

$\mathrm{C}=$ child $; \mathrm{T}=$ therapist. 
descriptions. ${ }^{8}$ Furthermore, the data reinforce the conception that in PDT treatment for children with ED the setting needs to be adapted so that the therapist is less interpretative and more supportive and expressive, maintaining an educative, encouraging, and empathic stance. ${ }^{42}$ This PDT modality, besides diverging from its classical assumptions, is also conceptually distinct from the prototypical CBT process, in being a specific form of treatment. Considering the statistical differentiation between the PDT and CBT prototypes for children with ID and ED, hypothesis 2 was partially confirmed.

The weak correlation between the prototypes developed in this study was expected, because the analysis produces empirical differentiation between psychotherapy approaches. In contrast, comparison of the Brazilian prototypes with those developed by Goodman et al. ${ }^{8}$ confirmed that the CBT Brazilian prototype is significantly correlated with the international CBT and PDT prototypes. Both Brazilian PDT prototypes significantly correlated with the international prototype of the same approach, but did not correlate significantly with the international CBT prototype.

The significant CBT correlation with all international prototypes may indicate an integrative trend in this approach, which is a notion introduced by Alford and Beck $^{28}$ and is currently growing with the development of third-wave therapies. ${ }^{43}$ Another hypothesis raised is that the concentration of responses - internalizing and externalizing - influenced the correlation between the prototypes because factor 1 encompasses treatments for children with different needs. The weak and statistically non-significant correlations between both Brazilian PDT prototypes and the international CBT prototype presented a reverse trend to that reported by Yoshida et al. ${ }^{44}$ who indicated that Brazilian psychodynamic psychotherapists working with adult patients tend to adopt more integrative approaches than their NorthAmerican counterparts.

\section{Final considerations}

This study developed Brazilian CBT and PDT prototypes for children with ID and ED. Similar to previous studies, the $\mathrm{Q}$ methodology proved effective for examining prototypical psychotherapy process conceptualizations.

While the CBT model may be stable for care of children with ID and ED, the PDT prototypes exhibited significant differences between treatment for children with distinct symptoms. In this sense, the PDT process, based on interpretation and insight, may not be suited for patients with ED, requiring flexibility in the setting.
Furthermore, the prototypes developed in this study are new tools for investigation of the therapeutic process with children, and they can be used in analysis of videorecorded psychotherapies, whether manualized or naturalistic. Investigation of the relationships between the prototypes and real cases will help to build a deeper understanding of what prototypical features are present in the psychotherapies offered and how they relate to outcomes.

Finally, we emphasize that the prototypes presented here were developed based on the opinions of experts predominantly from southern Brazil. Thus, it is noted that these findings may not reflect the situation in other regions in the country. When using the $\mathrm{Q}$ methodology and the types of analysis employed, the number of observations required (in this case, the 100 items of the $\mathrm{CPQ}$ ) must be significantly greater than the number of variables (in this study, the experts in psychotherapy), making larger expert samples impossible. Other studies that investigate prototypes in other localities could contribute to increasing understanding of differences and similarities between conceptions of the psychotherapeutic process.

\section{Acknowledgements}

This study was supported financially by Coordenação de Aperfeiçoamento de Pessoal de Nível Superior (CAPES) and Conselho Nacional de Desenvolvimento Científico e Tecnológico (CNPq).

\section{Disclosure}

No conflicts of interest declared concerning the publication of this article.

\section{References}

1. Chorpita BF, Daleiden EL, Ebesutani C, Young J, Becker KD, Nakamura BJ, et al. Evidence-based treatments for children and adolescents: an updated review of indicators of efficacy and effectiveness. Clin Psychol Sci Pract. 2011;18:154-72.

2. Midgley N, O'Keeffe S, French L, Kennedy E. Psychodynamic psychotherapy for children and adolescents: an updated narrative review of the evidence base. J Child Psychother. 2017;37:1-23.

3. Kazdin AE. Understanding how and why psychotherapy leads to change. Psychother Res. 2009;19:418-28.

4. Ablon JS, Jones EE. How expert clinicians' prototypes of an ideal treatment correlate with outcome in psychodynamic and cognitive-behavioral therapy. Psychother Res. 1998;8:71-83.

5. Serralta FB, Ablon JS. Development of Brazilian prototypes for short-term psychotherapies. Trends Psychiatry Psychother. 2016;38:71-9.

6. Ablon JS, Jones EE. Validity of controlled clinical trials of psychotherapy: findings from the NIMH treatment of depression collaborativeresearch program. Am J Psychiatry. 2002;159:775-83. 
7. Serralta FB, Pole N, Nunes MLT, Eizirik CL, Olsen C. The process of change in brief psychotherapy: effects of psychodynamic and cognitive-behavioral prototypes. Psychother Res. 2010 Sep;20:564-75.

8. Goodman G, Midgley N, Schneider C. Expert clinicians' prototypes of an ideal child treatment in psychodynamic and cognitivebehavioral therapy: Is mentalization seen as a common process factor? Psychother Res. 2016;26:590-601.

9. Schneider $\mathrm{C}$, Jones EE. Child psychotherapy Q-set coding manual [Internet]. Berkeley: University of California; 2009. [cited 2018 Jan 3]. http://www.homepages.ucl.ac.uk/ ucjtaca/cpqmanual. pdf

10. Jones EE. Psychotherapy process Q-set coding manual [Internet]. Berkeley; 1985 [cited 2017 Dec 20]. http://www.homepages.ucl. ac.uk/ ucjtaca/pqsmanual.pdf

11. Fonagy $P$ Bateman $A W$, Luyten $P$. Introduction and overview. In: Bateman AW, Fonagy $P$, editors. Handbook of mentalizing in mental health practice. Washington: American Psychiatric Publishing; 2012. p. 3-42.

12. Goodman G. The return of the repressed: single-case and multiple-case research designs to assess processes of therapeutic change. In: Goodman G, editor. Transforming the internal world and attachment: theoretical and empirical perspectives. Lanham: Jason Aronson; 2010. p. 47-98.

13. Gastaud MB, Carvalho C, Goodman G, Ramires VRR. Assessing levels of similarity to a "psychodynamic prototype" in psychodynamic psychotherapy with children: a case study approach (preliminary findings). Trends Psychiatry Psychother. 2015;37:161-5.

14. Ramires VRR, Godinho LBR, Goodman G. The therapeutic process of a child diagnosed with disruptive mood dysregulation disorder. Psychoanal Psychol. 2017;34:488-98.

15. Goodman G, Reed P, Athey-Lloyd L. Mentalization and play therapy processes between two therapists and a child with Asperger's disorder. Int J Play Ther. 2015;24:13-29.

16. Caspi A, Houts RM, Belsky DW, Goldman-Mellor SJ, Harrington $\mathrm{H}$, Israel $\mathrm{S}$, et al. The $\mathrm{p}$ factor: one general psychopathology factor in the structure of psychiatric disorders? Clin Psychol Sci. 2014; $14: 119-37$.

17. Achenbach TM, Edelbrock CS. Behavioral problems and competencies reported by parents of normal and disturbed children aged four through sixteen. Monogr Soc Res Child Dev. 1981;46:1-82.

18. Wilkinson P. Conceptualization about internalizing problems in children and adolescents. Cien Saude Colet. 2009;14:373-81.

19. Oland AA, Shaw DS. Pure versus co-occurring externalizing and internalizing symptoms in children: the potential role of socio-developmental milestones. Clin Child Fam Psychol Rev. 2005; 8:247-70.

20. Gresham FM, Lane KL, MacMillian DL. Social and academic profiles of externalizing and internalizing groups: risk factors for emotional and behavioural disorders. Behav Disord. 1999;24:231-45.

21. Benetti SP, Eisswein GC, Silva NB, Bernardi GSC, Calderon A. Adolescent psychotherapy process research: adaptation of the instrument APQ. Psico-USF. 2017;22:197-205.

22. Schneider C, Jones EE. Appendix IB. Child psychotherapy Q-set. Coding manual. In: Levy RA, Ablon JS, Kächele $\mathrm{H}$, editors. Psychodynamic psychotherapy research: evidence-based practice and practice-based evidence. New York: Humana Press; 2012. p. 611-26.

23. Ramires VRR, Schneider C. Psicoterapia de crianças: desenvolvimento da versão em português do Child psychotherapy Q-set. Psicol Teor Pesq. 2016;32:e323218.

24. Goodman G, Athey-Lloyd L. Interaction structures between a child and two therapists in the psychodynamic treatment of a child with Asperger's disorder. J Child Psychother. 2011;37:31126.

25. Ramires VRR, Carvalho C, Schmidt FMD, Fiorini GP, Goodman G. Interaction structures in the psychodynamic therapy of a boy diagnosed with Asperger's disorder: a single-case study. Res Psychother Psychopathol Process Outcome. 2015;18:129-40.
26. Schneider C, Midgley N, Duncan A. A "motion portrait" of a psychodynamic treatment of an 11-year-old girl: exploring interrelations of psychotherapy process and outcome using the child psychotherapy Q-set. J Infant Child Adolesc Psychother. 2010;9:94-107.

27. Hinkle DE, Wiersma W, Jurs SG. Applied statistics for the behavioral sciences. Boston: Houghton Mifflin; 2003.

28. Alford BA, Beck AT. An analysis of integrative ideology. In: Alford BA, Beck AT, editors. The integrative power of cognitive therapy. New York: The Guilford Press; 1997. p. 75-93.

29. Manassis K. Cognitive behavioral therapy with children: a guide for the community practitioner. New York: Routledge; 2009.

30. Weisz JR, Southam-Gerow MA, Gordis EB, Connor-Smith J. Primary and secondary control enhancement training for youth depression: applying the deployment-focused model of treatment development and testing. In: Weisz JR, Kazdin AE, editors. Evidence-based psychotherapies for children and adolescents. New York: The Guilford Press; 2003. p. 165-82.

31. Stallard P. Core components of CBT programmes for internalising problems. In: Stallard P, editor. A clinician's guide to think good feel good using CBT with children and young people. Chichester: John Wiley \& Sons; 2005. p. 129-44.

32. Petersen CS. Evidências de efetividade e procedimentos básicos para Terapia cognitivo-comportamental para crianças com transtornos de ansiedade. Rev Bras Psicoter. 2011;13:39-50.

33. Kendall PC, Hedtke KA. Coping cat workbook. Philadelphia: Workbook Publishing; 2006.

34. Sukhodolsky DG, Smith SD, Mccauley SA, Ibrahim K, Piasecka JB. Behavioral interventions for anger, irritability, and aggression in children and adolescents. J Child Adolesc Psychopharmacol. 2016;26:58-64.

35. Powell NP, Lochman JE, Boxmeyer CL, Barry TD, Pardini DA. The coping power program for aggressive behavior in children. In: Weisz JR, Kazdin AE, editors. Evidence-based psychotherapies for children and adolescents. New York/London: The Guilford Press; 2017. p. 159-76.

36. Aveline $M$, Strauss $B$, Stiles WB. Psychotheray research. In: Gabbard GO, Beck JS, Holmes J, editors. Oxford textbook of psychotherapy. Oxford: Oxford University Press; 2005. p. 44962.

37. Stallard P. A clinicians guide to think good, feel good: using CTB with children and young people. In: Stallard $P$, editor. Chichester: John Wiley \& Sons; 2005.

38. Pelham WE, Fabiano GA. Evidence-based psychosocial treatments for attention-deficit/hyperactivity disorder. J Clin Child Adolesc Psychol. 2008;37:184-214.

39. Eyberg SM, Nelson MM, Boggs SR. Evidence-based psychosocial treatments for children and adolescents with disruptive behavior. J Clin Child Adolesc Psychol. 2008;37:215-37.

40. Gabbard GO. Principais modalidades: psicanalítica/psicodinâmica. In: Gabbard GO, Beck JS, Holmes J, editors. Compêndio de psicoterapia de Oxford. Porto Alegre: Artmed; 2007. p. 14-29.

41. Zavaschi ML, Bassols AM, Bergmann DS, Mardini V. Abordagem psicodinâmica na infância. In: Eizirik CL, Aguiar RW, Schestatsky SS, editors. Psicoterapia de orientação analítica. Porto Alegre: Artmed; 2015. p. 723-54.

42. Kernberg PB, Chazan S. Children with conduct disorders: a psychotherapy manual. New York: Basic Books; 1991.

43. Farrel JM, Reiss N, Shaw IA. The schema therapy clinician's guide. Chichester: John Wiley \& Sons; 2014.

44. Yoshida EMP, Santeiro TV, Santeiro FRM, Rocha GMA. Psicoterapias breves psicodinâmicas: características da produção científica nacional e estrangeira (1980/2003). Psico-USF. 2004;10:51-9.

\section{Correspondence:}

Guilherme Fiorini

Department of Clinical, Educational and Health Psychology -

University College London

1-19 Torrington Place

WC1E 7HB - London, UK

E-mail: guilherme.fiorini@outlook.com 